\title{
Locked-in Syndrome due to Central Pontine Myelinolysis: Case Report
}

\author{
Min Kyun Sohn, MD, Jin Hee Nam, MD
}

Department of Rehabilitation Medicine, Chungnam National University School of Medicine, Daejeon, Korea

Central pontine myelinolysis (CPM) classically occurs in alcoholics, malnourished individuals, chronic liver diseases, and rapid correction of hyponatremia. This report presents locked-in syndrome due to CPM following rapid correction of hyponatremia. A 44-year-old male came to the hospital due to a short period of loss of consciousness. He was alert and had no focal neurological abnormalities at admission. The serum sodium concentration was $118 \mathrm{mEq} / \mathrm{L}$ and was corrected to $134 \mathrm{mEq} / \mathrm{L}$ in the first 18 hours. One week later, progressive weakness in limbs developed and he progressed to a complete quadriplegic state and bulbar palsy, with only eye blinking preserved. Brain magnetic resonance imaging revealed a characteristic hyperintense signal abnormality in both pons, so he was diagnosed to locked-in syndrome caused by CPM. The patient gradually improved following continuous intensive rehabilitation for more than 2 years. He was able to move all joint muscles against gravity in generally and he could gait under supervision.

Keywords Central pontine myelinolysis, Quadriplegia, Recovery of function

\section{INTRODUCTION}

Central pontine myelinolysis (CPM), first described by Adams et al. [1], is caused by disappearance of neurons and myelin comprising the central pontine. The exact incidence of CPM is unknown. In a study of 3,000 brains examined postmortem 15 cases of asymptomatic CPM were evident [2]. Lampl and Yazdi [3] reported 39.4\% of patients of CPM were diagnosed with alcohol poison-

Received August 22, 2013; Accepted December 4, 2013

Corresponding author: Jin Hee Nam

Department of Rehabilitation Medicine, Chungnam National University Hospital, 282 Munhwa-ro, Jung-gu, Daejeon 301-721, Korea

Tel: +82-42-338-2460, Fax: +82-42-338-2461, E-mail: shapil21@cnuh. co.kr

(c) This is an open-access article distributed under the terms of the Creative Commons Attribution Non-Commercial License (http://creativecommons. org/licenses/by-nc/3.0) which permits unrestricted noncommercial use, distribution, and reproduction in any medium, provided the original work is properly cited.

Copyright (C) 2014 by Korean Academy of Rehabilitation Medicine ing, $21.5 \%$ had a history of correcting hyponatremia, and $17.4 \%$ received a liver transplantation.

Clinical presentation of CPM is highly variable from asymptomatic to coma depending on the location of the lesion. The severity of the clinical presentation does not correlate with the size of the lesion [4]. Patients typically experience a rapidly evolving paraparesis or quadriparesis, and pseudobulbar symptoms like dysarthria and dysphagia. They may present with 'locked-in syndrome' in which intellectual activity is preserved but cannot be expressed because of a total incapacity to produce voluntary responses.

Although earlier reports on CPM described very poor outcome with mortality rates as high as $50 \%$ in the first 2 weeks after presentation and $90 \%$ at 6 months, recent reports suggest the decreased mortality mainly due to early diagnosis and improved intensive care treatment [5]. When patients survive their illness, most have significant 
neurological deficit. There were no reports of neurologic recovery after diagnosis of locked-in syndrome caused by $\mathrm{CPM}$ in Korea.

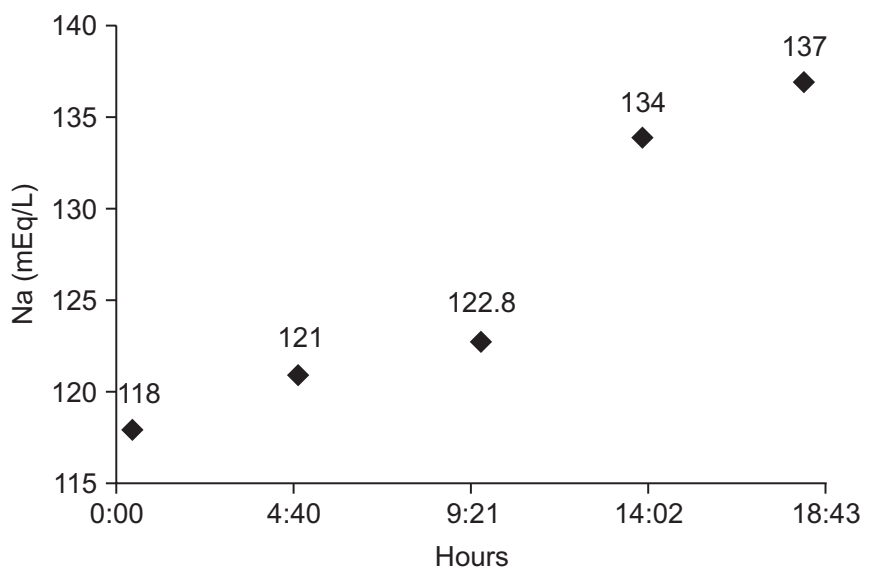

Fig. 1. Changes in serum sodium $(\mathrm{Na})$ concentrations during the first day.
We report a patient diagnosed with locked-in syndrome due to CPM, whose ability to perform daily living and muscle power were continuously improved after comprehensive rehabilitation treatment for more than 2 years.

\section{CASE REPORT}

A 44-year-old Korean male was admitted to the hospital because of a dizziness-induced fall and 1-minute loss of consciousness. The patient had a history of drinking two or more bottles of alcohol every day and had not eaten for the previous month.

On initial physical examination, he was alert and no focal neurological abnormalities were noted. Laboratory data revealed hyponatremia (serum sodium $118 \mathrm{mEq} / \mathrm{L}$ ), hypokalemia (potassium $2.5 \mathrm{mEq} / \mathrm{L}$ ), hypoalbuminemia (albumin $3.2 \mathrm{~g} / \mathrm{dL}$ ), abnormal liver function (aspartate transaminase $175 \mathrm{IU} / \mathrm{L}$ and alanine transaminase $68 \mathrm{IU} /$
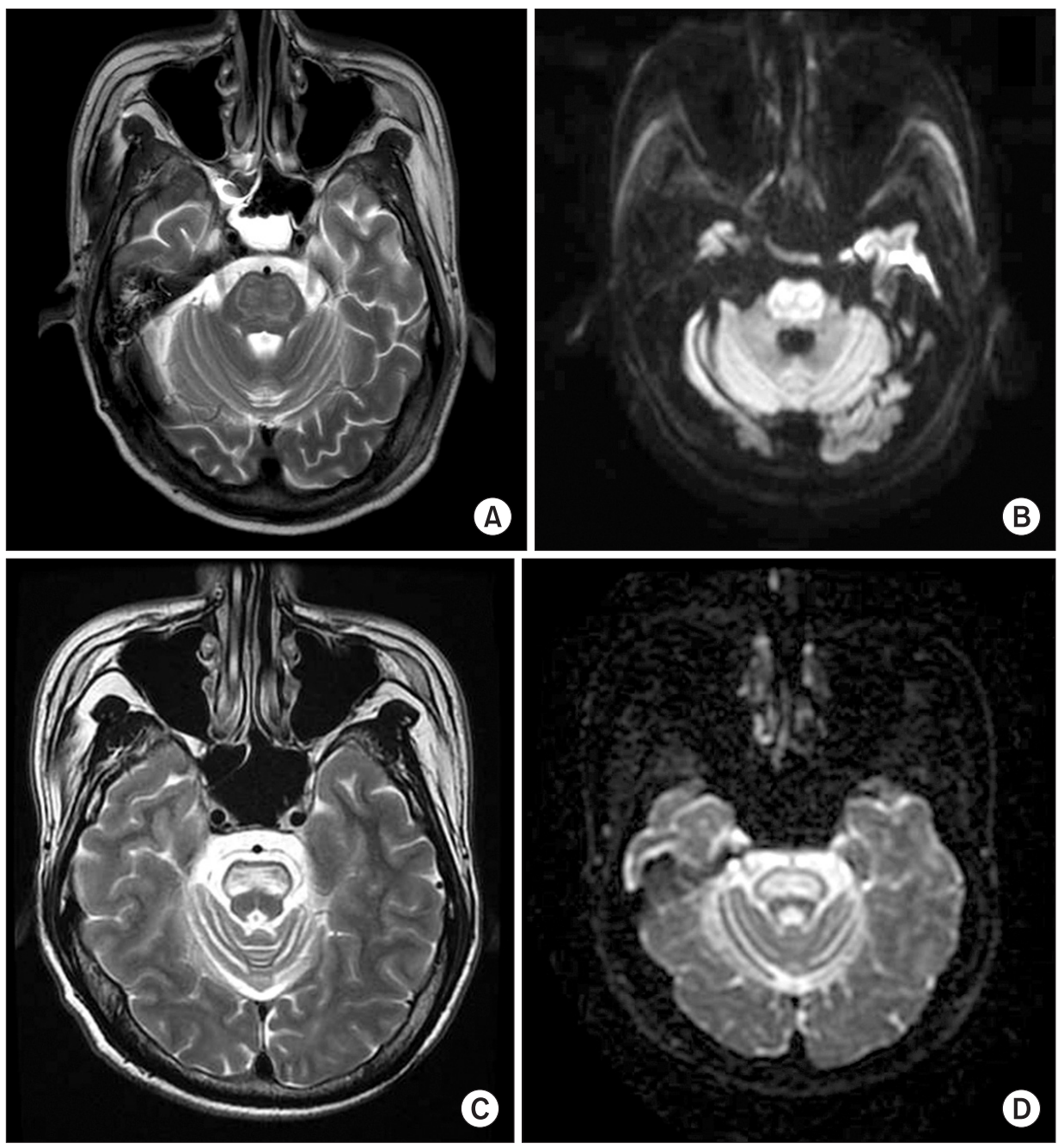

Fig. 2. (A, B) Brain MRI shows T2and diffusion-weighted imaging high signal intensity lesion in the bilateral pons, osmotic demyelination syndrome in pons 10 days after onset of symptoms. (C, D) Encephalomalacia at the site of initial high signal intensity lesion in pons after 1 year. 
L). Serum sodium concentration was corrected to 134 $\mathrm{mEq} / \mathrm{L}$ during the first 14 hours and $137 \mathrm{mEq} / \mathrm{L}$ within 18 hours following intravenous injection of $3 \%$ saline (Fig. 1).

One week after admission, progressive dysarthria, dysphagia, and weakness in limbs developed, so he was transferred to the intensive care unit. Feeding nasogastric and tracheostomy tubes were inserted and ventilator care was started. Brain magnetic resonance imaging (MRI) showed symmetrical areas of signal hyperintensity in the bilateral pons on T2-weighted images and diffusionweighted imaging, consistent with a diagnosis of CPM (Fig. 2A, 2B). Although he remained conscious, complete facial, bulbar, and limb muscle palsy developed with only eye blinking and eyeball movement preserved. He was moved to the general ward 3 weeks later and transferred to the Department of Rehabilitation Medicine 2 months later. His transfer was delayed due to fever and anal abscess.

At transfer to rehabilitation the patient presented with

Table 1. Clinical data after 2 years of comprehensive rehabilitation

\begin{tabular}{lc}
\hline \multicolumn{1}{c}{ Variable } & Value \\
\hline Medical Research Council & \\
\hline Shoulder abductor & $4(5) / 4(5)$ \\
\hline Elbow flexor & $4(5) / 4(5)$ \\
\hline Finger flexor & $4(5) / 4(5)$ \\
\hline Finger extensor & $4(5) / 4(5)$ \\
\hline Hip flexor & $4(5) / 4(5)$ \\
\hline Knee extensor & $4(5) / 4(5)$ \\
\hline Ankle dorsiflexor & $76(100) / 76(100)$ \\
Motricity index & $75(100) / 75(100)$ \\
\hline Upper extremity & $76(100) / 76(100)$ \\
\hline Lower extremity & $42(56)$ \\
\hline Total & $6(14 \pm 2.3) / 6(14 \pm 2.1)$ \\
\hline $\begin{array}{l}\text { Berg Balance Score } \\
\text { Purdue pegboard test }\end{array}$ & $51(109.9) / 48(100.8)$ \\
Grip power (lb) & $31.25(76.9) / 31.84(75.8)$ \\
Box-block test & $46(18.35) / 48(19.57)$ \\
\hline $\begin{array}{l}\text { Nine-hole pegboard test } \\
\text { (second) }\end{array}$ & \\
\hline
\end{tabular}

Values are presented as number (full score of scale or age-and sex-matched normal control data for the Purdue pegboard test, grip power, box-block test, and nine-hole pegboard). severe flaccid bulbar and limb paralysis, and the Korean version of Modified Barthel Index (K-MBI) score was 0 . Median and tibial somatosensory evoked potentials showed no response bilaterally. Comprehensive rehabilitation including general reconditioning and functional training to prevent deconditioning and contracture, and improve muscle power and cardiopulmonary function, electrical stimulation, and oromotor facilitation training were performed. Muscle power and physical function gradually improved. After 2 years, he could walk with supervision (Motricity index: upper extremity $76 / 76$, lower extremity 75/75, total 76/76, Berg Balance Score 42; 10-m walking test 17 seconds; timed to up and go 22 seconds; 6 -minute walking distance $90 \mathrm{~m}$ ). He could use his hands in activity (Purdue pegboard score 6/6, grip power 51 $\mathrm{lb} / 48 \mathrm{lb}$ ) (Table 1). He could write a letter and communicate by language. The tracheostomy tube was removed. Although dysphagia gradually improved, he still maintained percutaneous endoscopic gastrostomy.

Follow-up brain MRI repeated one year later showed encephalomalacia at the site of T2-high signal intensity lesion in pons (Fig. 2C, 2D). And follow-up median and tibial somatosensory evoked potentials showed prolonged latency of N19, P23, P37, N45 potentials bilaterally (Fig. 3).

\section{DISCUSSION}

CPM has traditionally been associated with rapid correction of hyponatremia, but the etiology has not been clearly established. Alcoholism, chronic malnutrition, and sodium imbalance are the primary conditions reported with CPM [1]. Diagnosis of CPM is based on clinical neurologic examination and confirmed by imaging studies. MRI is the primary method for diagnosis and is superior to computed tomography [6].

Rapid correction of hyponatremia (i.e., $>12 \mathrm{mEq} /$ day) poses a higher risk of developing CPM [7]. In this case, sodium level rapidly corrected to $137 \mathrm{mEq} / \mathrm{L}$ from 118 $\mathrm{mEq} / \mathrm{L}$ within 18 hours. Neurological symptoms that included quadriplegia, dysphagia, and dysarthria developed after 1 week. Brain MRI showed symmetrical areas of signal hyper intensity in the pons on T2-weighted images, consistent with a diagnosis of CPM. Diffusionweighted imaging confirmed the presence of hyperintensity at the same areas. The patient developed severe 
A

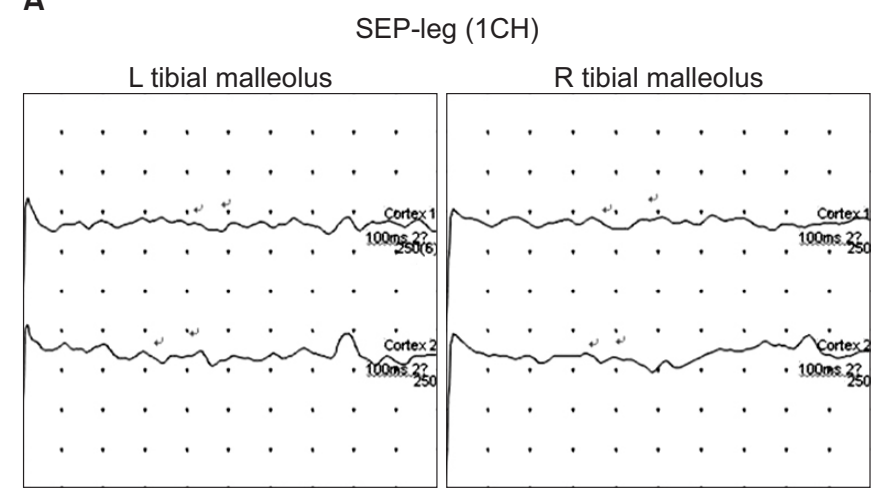

SEP-arm $(1 \mathrm{CH})$

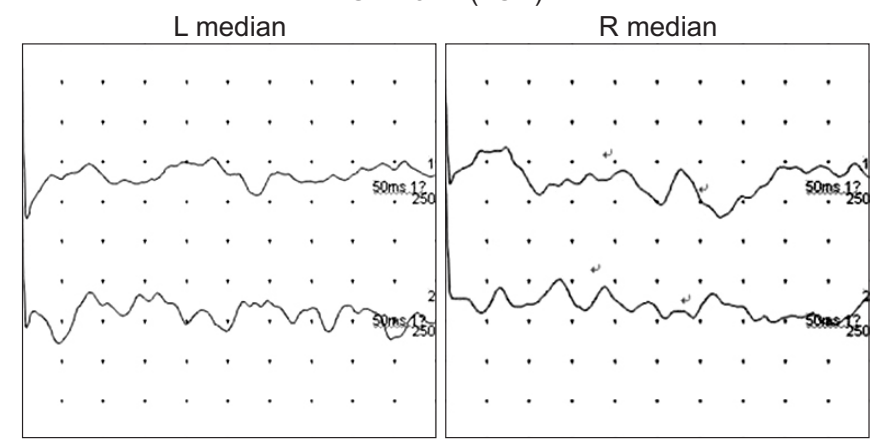

B
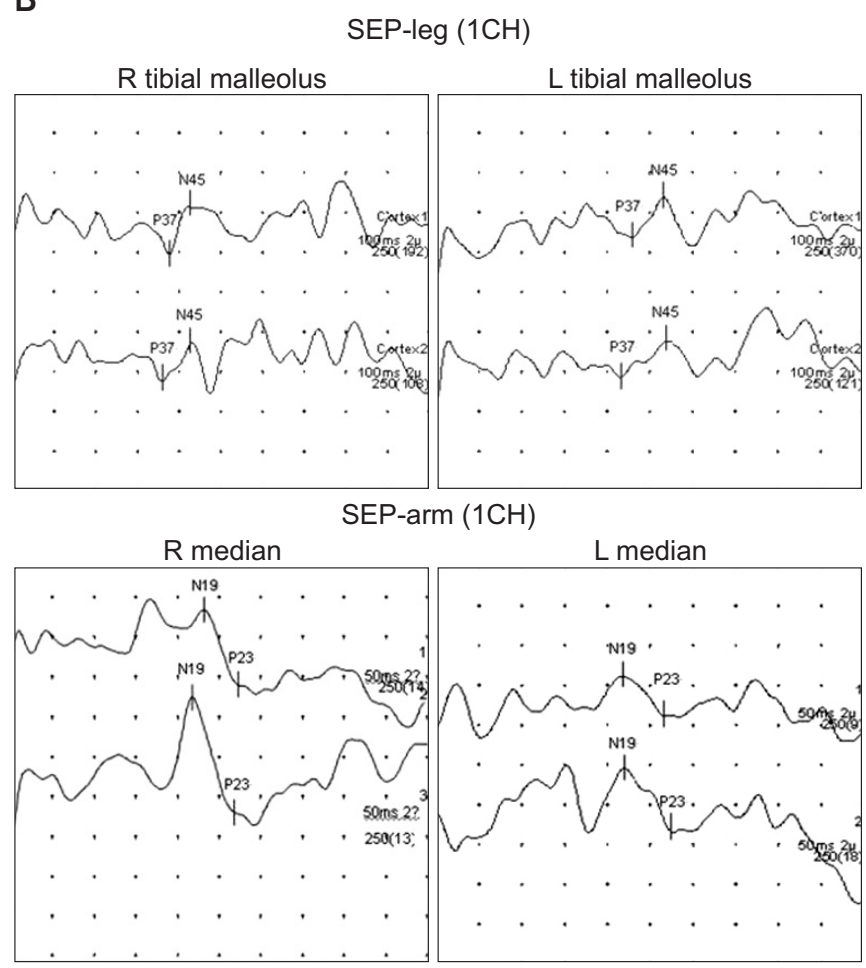

Fig. 3. (A) Somatosensory evoked potential (SEP) study stimulating both tibial nerves and median nerves shows absent potentials, bilaterally at first admission. (B) SEP study stimulating the tibial nerve shows prolonged latency of P37, N45 potentials, bilaterally and SEP study stimulating both median nerves shows prolonged latency of N19, P23 potentials at 3 years after onset.

flaccid quadriplegia associated with dysarthria and dysphasia. Eventually, the patient was diagnosed as lockedin syndrome caused by CPM.

Previous studies have reported on the heterogeneous prognosis of quadriplegia in patients with locked-in syndrome $[7,8]$. These studies suggested the possibility of several types of motor recovery mechanisms for lockedin syndrome. Kwon and Jang [6] reported on a quadriplegic patient with bilateral pontine infarcts, whose motor function appeared to be reorganized into the lateral areas of the pontine infarcts. Less severe hyponatremia (>115 $\mathrm{mEq} / \mathrm{L}$ ), absence of superadded hypokalemia, and higher Glasgow Coma Scale $(\geq 11)$ at the time of admission and at discharge are good prognostic factors in osmotic demyelination syndrome [8]. Also, the neurologic recovery rate of locked-in syndrome caused by non-vascular lesion is faster than that of avascular causes and more complete recovery is evident in locked-in syndrome due to non-vascular cause [9]. In this case, the patient was in a complete quadriplegic state but gradually recovered to antigravity power and could walk unaided after 2 years of comprehensive rehabilitation. Although he had very severe locked-in syndrome, some favorable prognostic factors were present. These included non-vascular cause locked-in syndrome, initial sodium level of $118 \mathrm{mEq} / \mathrm{L}$ ( $\geq 115 \mathrm{mEq} / \mathrm{L}$ ), good Glasgow Coma Scale score, and preserved lateral area of the pons on brain MRI. In addition, comprehensive rehabilitation worked as a good prognostic factor.

In conclusion, if blood test showed hyponatremia, care must be taken to avoid develop CPM following rapid correction of hyponatremia. Diagnosis as CPM with clinically confirmed locked-in syndrome necessitates further studies to evaluate prognostic factors, and early comprehensive rehabilitation are recommended for recovery from neurological deficits as soon as possible.

\section{CONFLICT OF INTEREST}

No potential conflict of interest relevant to this article was reported. 


\section{REFERENCES}

1. Adams RD, Victor M, Mancall EL. Central pontine myelinolysis. Arch Neurol Psychiatry 1959;81:154-72.

2. Newell KL, Kleinschmidt-DeMasters BK. Central pontine myelinolysis at autopsy; a twelve year retrospective analysis. J Neurol Sci 1996;142:134-9.

3. Lampl C, Yazdi K. Central pontine myelinolysis. Eur Neurol 2002;47:3-10.

4. Casanova E, Lazzari RE, Lotta S, Mazzucchi A. Lockedin syndrome: improvement in the prognosis after an early intensive multidisciplinary rehabilitation. Arch Phys Med Rehabil 2003;84:862-7.

5. Huang WY, Weng WC, Peng TI, Ro LS, Yang CW, Chen $\mathrm{KH}$. Central pontine and extrapontine myelinolysis after rapid correction of hyponatremia by hemodialysis in a uremic patient. Ren Fail 2007;29:635-8.

6. Kwon HG, Jang SH. Motor recovery mechanism in a quadriplegic patient with locked-in syndrome. NeuroRehabilitation 2012;30:113-7.

7. Sterns RH, Riggs JE, Schochet SS Jr. Osmotic demyelination syndrome following correction of hyponatremia. N Engl J Med 1986;314:1535-42.

8. Kallakatta RN, Radhakrishnan A, Fayaz RK, Unnikrishnan JP, Kesavadas C, Sarma SP. Clinical and functional outcome and factors predicting prognosis in osmotic demyelination syndrome (central pontine and/or extrapontine myelinolysis) in 25 patients. J Neurol Neurosurg Psychiatry 2011;82:326-31.

9. Patterson JR, Grabois M. Locked-in syndrome: a review of 139 cases. Stroke 1986;17:758-64. 